\title{
Prevalence and factors associated with small intestinal bacterial overgrowth in patients with Crohn's disease: a retrospective study at a referral center
}

\author{
Erika Ruback BERTGES ${ }^{1}$ and Júlio Maria Fonseca CHEBLI $^{2}$
}

\begin{abstract}
Background - Small intestinal bacterial overgrowth (SIBO) appears to be common in patients with Crohn's disease (CD). The rate of SIBO has been estimated at $25 \%-88 \%$ in this setting. However, different demographic, socioeconomic, and disease-related factors may exist between South American and North American or European populations that may limit the generalization of these findings, as the data are mainly derived from North American or European studies. Objective - We studied the prevalence and predictors of SIBO in CD outpatients. Methods - In this retrospective study, between June 2011 and June 2016, the medical records of $110 \mathrm{CD}$ patients were assessed for presence of SIBO using the $\mathrm{H}_{2} / \mathrm{CH}_{4}$ glucose breath test. Univariate analysis was performed to investigate the potential association between SIBO and demographic, disease-related data, systemic markers of inflammation (C-reactive protein and erythrocyte sedimentation rate). Results - The SIBO rate was high in CD patients (30\%). Patients with and without SIBO were comparable according to demographics, systemic inflammatory biomarkers, and disease characteristics, except to the stricturing phenotype more common in the SIBO-positive CD patients $(48.5 \%$ vs $19.5 \%, P=0.001)$. Conclusion - In Brazilian CD patients, SIBO is a highly prevalent condition. Stricturing phenotype demonstrated association with SIBO. An individualized screening plan followed by the timely treatment for SIBO should be carried out as part of quality of care improvement in CD individuals.
\end{abstract}

HEADINGS - Inflammatory bowel diseases. Crohn disease. Small intestine, microbiology. Bacterial infections. Demographic data.

\section{INTRODUCTION}

Small intestinal bacterial overgrowth (SIBO) consists of increased and/or abnormal microbiota comprising different bacterial species derived from the colonic flora that ascend to small intestine segments and may be associated with a myriad of gastrointestinal symptoms and extraintestinal complications ${ }^{(1)}$.

The clinical diagnosis of SIBO is difficult to establish, as its most common symptoms are observed in several disorders, delaying its detection and early treatment ${ }^{(2)}$. The main complaints reported by patients with SIBO include bloating, flatulence, abdominal pain and/or discomfort, and diarrhea ${ }^{(2,3)}$. The presence of more than $10^{5}$ colony-forming units per milliliter $(\mathrm{CFU} / \mathrm{mL})$ of colonic-type bacteria in jejunal aspirate culture is the traditionally accepted gold standard for diagnosing $\mathrm{SIBO}^{(4)}$. However, it is a difficult and invasive, time-consuming and costly technique that is subject to sample contamination $^{(2,4)}$. In clinical practice, culturing has been replaced by hydrogen breath testing ${ }^{(3,4)}$. The principle of these tests is that colonic bacteria have the ability to metabolize nonabsorbable carbohydrates into hydrogen $\left(\mathrm{H}_{2}\right)$ and/or methane $\left(\mathrm{CH}_{4}\right)$ gas, which are readily absorbed through the intestinal epithelium, to finally be excreted in expired air ${ }^{(5)}$. The two main tests used in clinical practice are the hydrogen breath test using glucose or lactulose as substrates; notably, the test that uses the former substrate shows higher accuracy ${ }^{(6,7)}$.
Crohn's disease (CD) is a multisystemic chronic inflammatory disease that is transmural, immune-mediated and, thus far, incurable and affects any part of the gastrointestinal $\operatorname{tract}^{(8)}$. SIBO seems to be a common condition in patients with $\mathrm{CD}$, with an estimated prevalence between $25 \%$ and $88 \%$, and predominant in patients with gastrocolic or jejunocolic fistulas, stasis of intestinal contents, colo-ileal reflux caused by the loss of the ileocecal valve, surgical blind loop, intestinal obstruction and different types of motility disorders ${ }^{(1,9)}$.

Despite the well-known association of SIBO and CD, there are few published studies with a large patient sample $e^{(3,6)}$. In many cases, SIBO in patients with CD is underdiagnosed due to the similarity of symptoms between the two diseases, and in some patients, SIBO can mimic CD exacerbation. Consequently, unnecessary therapies may be instituted, such as corticosteroids, immunosuppressants and biologics, resulting in increased costs and risks of adverse effects, in addition to not leading to significant improvement in the clinical status. In turn, the simple administration of antibiotics (one-time or multiple-cycle treatment) can be sufficient to resolve symptoms in these individuals ${ }^{(3,10)}$. In the clinical scenario of CD complicated by SIBO, bacterial overgrowth may cause disturbances in the small intestine mucosa with consequent defects in the brush border and deconjugation of bile salts, sometimes causing or exacerbating fat malabsorption, micronutrient deficiencies, anemia and weight $\operatorname{loss}^{(1)}$.

${ }^{1}$ Faculdade de Ciências Médicas e da Saúde de Juiz de Fora - SUPREMA, MG, Brasil. ² Universidade Federal de Juiz de Fora, Clínica Médica, Juiz de Fora, MG, Brasil.

Corresponding author: Erika Ruback Bertges. E-mail: erikabertges@yahoo.com.br 
Knowing the prevalence and the predisposing factors of SIBO in a population of patients with $\mathrm{CD}$ in our setting is important so that we can establish strategies aimed at the diagnosis and treatment of patients at greater risk of presenting this clinical association.

This retrospective study evaluated the prevalence of and factors associated with SIBO in patients with CD followed-up at the Inflammatory Bowel Diseases Center (IBD), University Hospital of the Federal University of Juiz de Fora (Hospital Universitário da Universidade Federal de Juiz de Fora - HU-UFJF), located in Minas Gerais, Brazil.

\section{METHODS}

\section{Study design}

In this retrospective study, all the electronic medical records of adult patients ( $\geq 18$ years old) with CD followed-up at the HU-UFJF IBD Center were reviewed to identify patients who underwent the hydrogen and methane breath test for investigation of SIBO in the period from June 2011 to June 2016. The present study was conducted in accordance with the Declaration of Helsinki and was approved by the institutional Research Ethics Committee.

\section{Analysis of electronic medical records}

The diagnosis of $\mathrm{CD}$ was previously established by a combination of clinical, radiological, endoscopic and anatomicalpathological findings ${ }^{(11)}$.

The medical records of patients with any of the following criteria were excluded from analysis: age under 18 years; presence of any infection; history of upper gastrointestinal tract surgery; presence of a stoma; history of colonoscopy preparation in the four weeks preceding the breath test; use of antibiotics or proton pump inhibitors in the four weeks preceding the breath test; concomitant diseases for which the prevalence of SIBO has been previously shown to be high, such as irritable bowel syndrome, multiple intestinal surgeries (but not a single intestinal resection), short bowel syndrome, celiac disease, chronic pancreatitis, liver cirrhosis, diabetes, nonalcoholic steatohepatitis, immunodeficiency syndromes, connective tissue diseases, chronic renal failure and neurological diseases $^{(1,2)}$. The medical records of pregnant or lactating women were not included in the analysis because breath tests are typically not performed in these conditions.

\section{Demographic and CD-related characteristics}

Once the patients with $\mathrm{CD}$ who underwent the breath test were identified, the eligibility criteria and clinical history were analyzed. The following data from the electronic medical records were compiled: sex, age, weight, height, body mass index (BMI), current smoking status and possible associated chronic diseases. CD-related characteristics were recorded, including time since diagnosis, patient age at diagnosis, disease location and behavior according to the Montreal classification ${ }^{(12)}$, disease activity (active or in remission), drugs in use at the time of the breath test and CD-related surgical history. Clinical indices, the Crohn's Disease Activity Index (CDAI) and the Harvey-Bradshaw Index (HBI) were used to quantify $\mathrm{CD}$ activity. Thus, a CDAI score $<150$ indicated remission, and higher scores indicated active disease; a HBI score $\geq 5$ indicated active disease ${ }^{(13)}$.

The presence or absence of symptoms consistent with SIBO, such as diarrhea ( $\geq 3$ watery or soft bowel movements per day), abdominal pain, bloating and flatulence, was recorded for each patient when present within three months before undergoing the breath test. To evaluate inflammation, the plasma levels of C-reactive protein (CRP) and the erythrocyte sedimentation rate (ESR) were considered when they were available within one month before undergoing the breath test. An increase in ESR $>20 \mathrm{~mm} /$ hour and CRP $>5 \mathrm{mg} / \mathrm{L}$ were considered to be elevated.

\section{Hydrogen and methane breath test}

The breath test protocol performed at the HU-UFJF IBD Center was as follows. One day before the breath test, patients were instructed to consume a diet low in fiber and carbohydrates and without dairy products. After 12 hours of fasting, patients were instructed to brush their teeth and wash their mouth with a chlorhexidine solution at least two hours before the test. Thus, false-positive results due to high baseline levels of $\mathrm{H}_{2}$ or $\mathrm{CH}_{4}$ resulting from bacterial fermentation in the oral cavity could be avoided ${ }^{(7)}$. Patients were instructed to avoid smoking cigarettes and/ or performing physical activity two hours before and during the test, preventing any respiratory influence on the expired $\mathrm{H}_{2} / \mathrm{CH}_{4}$ levels.

The tests were performed by professionals trained to perform the procedure, using a solution containing $50 \mathrm{~g}$ of glucose in 200 $\mathrm{mL}$ of water. A first sample of exhaled air after fasting was collected into a plastic bag, and then the substrate was administered. New samples were collected every 15 minutes in the first hour and every 30 minutes in the second hour, for a total of seven samples per patient, over a period of 120 minutes. The samples were then read on a BreathTracker DP® (QuinTron Instrument Company, Milwaukee, WI, USA). The presence of SIBO was defined as an increase in exhaled $\mathrm{H}_{2}$ and/or $\mathrm{CH}_{4}$ higher than 12 parts per million ( $\mathrm{ppm}$ ) relative to the baseline value in at least two consecutive samples within two hours ${ }^{(1,2)}$.

\section{Statistical analysis}

Statistical analysis was performed using SPSS 20.0 (SPSS, Chicago, IL, USA). The quantitative variables are expressed as the median and range or as the mean \pm standard deviation when normally distributed, and the categorical variables are expressed as absolute and relative frequencies. Descriptive statistics for all relevant variables for the groups were calculated. For data analysis, the patients were divided into two groups (individuals with and without SIBO) according to the results of the breath test. The comparisons between groups as well as possible relationships between the presence of SIBO and sociodemographic characteristics, CD-related data and serum inflammatory biomarkers were analyzed using Student's $t$ test for independent samples, Pearson's chi-square test or the Mann-Whitney U test, when appropriate. For the purpose of comparison, the level of statistical significance was set to $P<0.05$.

\section{RESULTS}

\section{Study population}

Among the 630 patients with $\mathrm{CD}$ followed-up at the IBD Center during the study period, $119(18.9 \%)$ adult patients with CD had undergone the hydrogen and methane breath test. Of these, nine $(7.6 \%)$ individuals were not included in the study because they did not meet the eligibility criteria: three had concomitant irritable bowel syndrome, two had recently used antibiotics, two had diabetes, one had steatohepatitis and on had celiac disease. Thus, the medical records of 110 patients ( 44 men, 66 women, mean age of $37.1 \pm 19.1$ years) were selected for the study (TABLE 1). The 
indications for performing the SIBO breath test were the presence of intestinal stenosis $(n=31)$ or internal fistula $(n=20)$, flatulence $(n=21)$, bloating $(n=18)$, diarrhea disproportionate to intestinal inflammation $(n=16)$ and "routine" $(n=4)$.

TABLE 1. Demographic characteristics, symptoms and results of the hydrogen and methane breath test for SIBO in patients with Crohn's disease.

\begin{tabular}{|c|c|}
\hline Characteristic & Patients \\
\hline Sex F/M, n (\%) & $66(60) / 44(40)$ \\
\hline Age (years)* & $37.1 \pm 19.1$ \\
\hline BMI $\left(\mathrm{kg} / \mathrm{m}^{2}\right)^{*}$ & $23.9 \pm 8.8$ \\
\hline Active smoking, $\mathrm{n}(\%)$ & $9(8.2)$ \\
\hline \multicolumn{2}{|c|}{ Symptoms (more than one symptom possible), n (\%) } \\
\hline Abdominal pain & $41(37.3)$ \\
\hline Bloating & $34(30.9)$ \\
\hline Flatulence & $21(19.1)$ \\
\hline Diarrhea & $18(16.4)$ \\
\hline \multicolumn{2}{|l|}{ Breath test } \\
\hline SIBO, n $(\%)$ & $33(30)$ \\
\hline Baseline $\mathrm{H}_{2}$ level $(\mathrm{ppm})^{*}$ & $7.2 \pm 13.4$ \\
\hline Baseline $\mathrm{CH}_{4}$ level $(\mathrm{ppm})^{*}$ & $4.9 \pm 7.8$ \\
\hline Peak $\mathrm{H}_{2}$ level (ppm)* & $19.7 \pm 39.7$ \\
\hline Peak $\mathrm{CH}_{4}$ level $(\mathrm{ppm}) *$ & $11.6 \pm 25.3$ \\
\hline
\end{tabular}

\section{Hydrogen and methane levels expired in the breath tests}

In the total CD population, $33(30 \%)$ patients had SIBO. The mean baseline levels of $\mathrm{H}_{2}$ and $\mathrm{CH}_{4}$ in the breath tests were 7.2 \pm 13.4 ppm and $4.9 \pm 7.8 \mathrm{ppm}$, respectively. The mean peak excretion of $\mathrm{H}_{2}$ was $19.7 \pm 39.7 \mathrm{ppm}$ and of $\mathrm{CH}_{4}$ was $11.6 \pm 25.3 \mathrm{ppm}$ (TABLE 1). The mean baseline levels of $\mathrm{H}_{2}$ and $\mathrm{CH}_{4}$ were $9.1 \pm 16.4$ ppm and $7.4 \pm 10.2$ ppm, respectively, in patients with $\mathrm{CD}$ and SIBO and 7.5 $\pm 13.8 \mathrm{ppm}$ and $6.3 \pm 9.1 \mathrm{ppm}$, respectively, in patients with CD without SIBO ( $P>0.05$ for both comparisons). While the mean peak $\mathrm{H}_{2}$ excretion was $35.3 \pm 66.2 \mathrm{ppm}$ in patients with $\mathrm{CD}$ and SIBO and 11.2 \pm 33.1 ppm in patients with CD without SIBO $(P=0.001)$, the former had a mean peak $\mathrm{CH}_{4}$ excretion of $12.8 \pm 18.3 \mathrm{ppm}$, and the latter had a mean peak $\mathrm{CH}_{4}$ excretion of $9.4 \pm 26.7 \mathrm{ppm}(P=0.24)$ (TABLE 2).

TABLE 2. Baseline inflammatory biomarkers and results of the hydrogen and methane breath test in patients with Crohn's disease according to the presence of SIBO.

\begin{tabular}{lccc}
\hline & SIBO & Without SIBO & $\boldsymbol{P}$ \\
\hline $\mathrm{CRP}(\mathrm{mg} / \mathrm{L}) \dagger$ & $1.4(0.5-19)$ & $1.7(0.5-320)$ & 0.64 \\
$\mathrm{CRP}>5 \mathrm{mg} / \mathrm{L}, \mathrm{n}(\%)$ & $8(24.2)$ & $18(23.4)$ & 0.92 \\
$\mathrm{ESR}(\mathrm{mm} / \mathrm{h}) \dagger$ & $12(5-45)$ & $15(2-90)$ & 0.59 \\
$\mathrm{ESR}>20 / \mathrm{h}, \mathrm{n}(\%)$ & $9(27.3)$ & $19(24.6)$ & 0.77 \\
Breath test & & & \\
Baseline $\mathrm{H}_{2}$ level $(\mathrm{ppm}) *$ & $9.1 \pm 16.4$ & $7.5 \pm 13.8$ & 0.48 \\
Baseline $\mathrm{CH}_{4}$ level (ppm)* & $7.4 \pm 10.2$ & $6.3 \pm 9.1$ & 0.34 \\
Peak $\mathrm{H}_{2}$ level $(\mathrm{ppm}) *$ & $35.3 \pm 66.2$ & $11.2 \pm 33.1$ & 0.001 \\
Peak $\mathrm{CH}_{4}$ level $(\mathrm{ppm}) *$ & $12.8 \pm 18.3$ & $9.4 \pm 26.7$ & 0.24 \\
\hline
\end{tabular}

$\dagger$ Median (range). *Mean \pm standard deviation. SIBO: small intestinal bacterial overgrowth; CRP: C-reactive protein; ESR: erythrocyte sedimentation rate; $\mathrm{H}_{2}$ : hydrogen in expired air; $\mathrm{CH}_{4}$ : methane in expired air
Twenty-two $(66.7 \%)$ of the 33 patients with CD and SIBO were diagnosed based on an increased level of expired $\mathrm{H}_{2}$ only, five (15.1\%) on an increased level of expired $\mathrm{CH}_{4}$ only and six $(18.2 \%)$ on increased expired levels of both $\mathrm{H}_{2}$ and $\mathrm{CH}_{4}$.

\section{Association of SIBO with clinical data and inflammatory biomarkers in CD}

TABLE 3 summarizes the demographic and clinical characteristics of the population with CD regarding to the presence of SIBO. Patients with concomitant CD and SIBO did not differ significantly from those with negative breath tests for SIBO in terms of demographics, BMI, smoking, location of $\mathrm{CD}$, disease duration, previous intestinal resection, treatment with corticosteroids, immunomodulators or anti-TNF- $\alpha$ agents. Similarly, there were no significant differences between the patients with and without SIBO

TABLE 3. Demographic and clinical characteristics of patients with Crohn's disease according to the presence of SIBO.

\begin{tabular}{|c|c|c|c|}
\hline & SIBO & $\begin{array}{c}\text { Without } \\
\text { SIBO }\end{array}$ & $P$ \\
\hline Sex, n $(\%)$ & & & 0.73 \\
\hline Female & $19(57.6)$ & $47(61)$ & \\
\hline Male & $14(42.4)$ & $30(39)$ & \\
\hline Age (years)* & $36.4 \pm 15.1$ & $37.5 \pm 18.3$ & 0.76 \\
\hline $\operatorname{BMI}\left(\mathrm{kg} / \mathrm{m}^{2}\right)^{*}$ & $23.5 \pm 8.8$ & $24.2 \pm 7.8$ & 0.68 \\
\hline Active smoking $\mathrm{n}(\%)$ & $3(9)$ & $6(7.8)$ & 0.82 \\
\hline CD location, n (\%) & & & 0.38 \\
\hline L1 & $15(45.5)$ & $31(40.2)$ & \\
\hline $\mathrm{L} 2$ & $5(15.1)$ & $21(27.3)$ & \\
\hline L3 & $13(39.4)$ & $25(32.5)$ & \\
\hline CD behavior $\mathrm{n}(\%)$ & & & 0.001 \\
\hline B1 & $10(30.3)$ & $50(64.9)$ & \\
\hline B2 & $16(48.5)$ & $15(19.5)$ & \\
\hline B3 & $7(21.1)$ & $12(15.6)$ & \\
\hline Disease duration (years)* & $6.5 \pm 8.9$ & $7.2 \pm 8.7$ & 0.70 \\
\hline CDAI* & $156 \pm 99$ & $146 \pm 96$ & 0.62 \\
\hline $\mathrm{CDAI}>150, \mathrm{n}(\%)$ & $7(21)$ & $11(14.3)$ & 0.43 \\
\hline HBI* & $4.2 \pm 3.6$ & $3.9 \pm 3.7$ & 0.69 \\
\hline $\mathrm{HBI} \geq 5, \mathrm{n}(\%)$ & $11(33.3)$ & $19(24.7)$ & 0.45 \\
\hline Previous intestinal resection, n (\%) & $10(30.3)$ & $16(20.8)$ & 0.28 \\
\hline \multicolumn{4}{|c|}{ Symptoms (more than one symptom possible), n (\%) } \\
\hline Abdominal pain & $14(42.4)$ & $27(35)$ & 0.46 \\
\hline Diarrhea & $11(33.3)$ & $23(29.9)$ & 0.72 \\
\hline Bloating & $6(18.2)$ & $12(15.6)$ & 0.73 \\
\hline Flatulence & $7(21.2)$ & $14(18.2)$ & 0.71 \\
\hline \multicolumn{4}{|l|}{ Current treatment, n (\%) } \\
\hline Corticosteroids & $7(21.1)$ & $15(19.5)$ & 0.83 \\
\hline Immunomodulators & $23(69.7)$ & $49(63.3)$ & 0.54 \\
\hline Anti-TNF- $\alpha$ agents & $9(27.2)$ & $19(24.7)$ & 0.77 \\
\hline
\end{tabular}

* Mean \pm standard deviation. SIBO: small intestinal bacterial overgrowth; BMI: body mass index; CD: Crohn's disease; L1: Ileal; L2: Colonic; L3: Ileocolonic; B1: Nonstenosing, nonpenetrating; B2: Stenosing; B3: Penetrating; CDAI: Crohn's disease activity index; HBI: Harvey-Bradshaw Index. 
in terms of mean CDAI score ( 156 vs 146 , respectively; $P=0.62$ ) or HBI score (4.2 vs 3.9, respectively; $P=0.69$ ). Of the patients with SIBO, $26(79 \%)$ had a CDAI score $<150$, and $22(66.7 \%)$ had an HBI score $<5$. In comparison, $66(85.7 \%)$ patients without SIBO had a CDAI score $<150$, and $58(75.3 \%)$ had an HBI score $<5$ ( $P>0.05$ for both comparisons). In contrast, individuals with SIBO were significantly more likely to have a stenosing phenotype than were patients without SIBO (48.5\% vs $19.5 \%)$, while the latter had nonstenosing and nonpenetrating disease more often than the former ( $30.3 \%$ vs $64.9 \%, P=0.001$ for both comparisons).

The main symptoms reported by patients with SIBO were abdominal pain $(37.3 \%)$, diarrhea $(30.9 \%)$, flatulence $(19.1 \%)$ and bloating (16.4\%) (TABLE 1). All reported symptoms were comparable between patients with and without SIBO (TABLE 3). Likewise, there was no difference in CRP levels or ESR elevation between the groups (TABLE 2).

\section{DISCUSSION}

In this retrospective study, SIBO was found to be a very prevalent disorder $(30 \%)$ in adult patients with CD, particularly in patients with a stenosing phenotype. The high prevalence of SIBO observed can be explained, at least in part, by the fact that in CD, there are several predisposing factors for SIBO, such as surgery involving the gastrointestinal tract, especially ileocecal resection, dysmotility and stenoses or fistulas ${ }^{(14)}$. The rate of SIBO in this study is in agreement with that reported in other studies in patients with $\mathrm{CD}$, ranging from $15 \%$ to $45 \%{ }^{(3,15-18)}$, suggesting that SIBO is a common complication in patients with $\mathrm{CD}$ in various populations worldwide. Ricci et al. ${ }^{(18)}$ found an increased prevalence of SIBO in patients with CD compared to controls (32.6\% vs $12.4 \%)$. In a recent systematic review and meta-analysis analyzing the prevalence of SIBO in patients with IBD conducted by Shah et al., which included 10 studies and a total of 846 patients with $C D$, the mean prevalence of SIBO was $25.4 \%$, very similar to our findings ${ }^{(17)}$.

In the present study, the presence of stenosis was associated with SIBO (48.5\% vs $19.5 \%)$, which is in accordance with data from the literature, as demonstrated by a systematic review of five case-control studies, which showed that the mean prevalence of SIBO in patients with fibrostenosing CD was $39.7 \%$, whereas in those with CD with an inflammatory phenotype was $21.19 \%$; i.e., the presence of stenosis increased by 7.5 times the odds of occurrence of SIBO in patients with $\mathrm{CD}^{(17)}$. The strong association of the stenosing phenotype with the presence of SIBO may be because stenoses located in the small intestine or in anastomoses cause stasis and prolonged intestinal transit, which favors jejunoileal bacterial proliferation $^{(3,6)}$.

In our study, there was no association of SIBO with a history of intestinal resection, a result that differs from some studies ${ }^{(10,19)}$ but that agrees with others ${ }^{(18,20)}$. Surgeries that affect the integrity of the ileocecal valve may be followed by changes in the bacterial colonization of the proximal ileum, mainly characterized by an increase in gram-negative species. The removal of the physiological barrier represented by the ileocecal valve allows reflux of colonic bacteria into the small intestine ${ }^{(21)}$. Shah et al. observed that a history of bowel surgery, especially resection of the ileocecal valve, increased the odds of SIBO in patients with CD by $2.4-$ fold $^{(17)}$. The fact that we excluded from the analysis patients with $\mathrm{CD}$ who had undergone more than two intestinal surgeries, which predispose patients to the development of SIBO, could explain the lack of association between SIBO and prior intestinal resection in the present study. One previous surgery involving a resection of less than $100 \mathrm{~cm}$ of the small intestine or a partial colon resection was accepted because, in general, it does not significantly interfere with intestinal transit.

Interestingly, the results for the parameters used to assess clinical activity (CDAI and HBI) and inflammation in CD (CRP and ESR) were not significantly different in patients with and without SIBO. Curiously, most patients with SIBO had CDAI and HBI scores compatible with clinical remission. This finding is in agreement with that of other studies ${ }^{(3,6,18)}$. It is important to note that some of the symptoms used in HBI and CDAI scores, such as abdominal pain and diarrhea, are common to both SIBO and $\mathrm{CD}$, which can be a limitation when analyzing a possible relationship between the presence of SIBO and these scores. In our series, intestinal inflammation was not evaluated by fecal calprotectin measurements, due to the unavailability of this test at the time the SIBO tests were performed, but it that was reviewed by Lee et al. ${ }^{(22)}$, who showed no significant difference in mean fecal calprotectin levels between patients with $\mathrm{CD}$ and positive and negative breath tests $(849.34 \mathrm{mg} / \mathrm{g}$ vs $1,035.96 \mathrm{mg} / \mathrm{g}$, respectively; $P=0.20)$. Although we did not evaluate mucosal healing in this series, the data from this study and from some studies suggest that even in patients with CD in clinical remission, the presence of SIBO should be considered and carefully investigated. Studies evaluating endoscopic healing are necessary to determine the true relationship between SIBO and mucosal inflammation.

It should be noted that in this population of patients with CD, there was no significant difference in serum CRP levels or in ESR between those with and without SIBO, which suggests that bacterial overgrowth restricted to the small intestine is not associated with systemic or intestinal inflammation in this clinical setting. It is well known that in SIBO, there is an increase in the release of bacterial products and serum endotoxins and, consequently, of proinflammatory cytokines ${ }^{(23)}$. Riordan et al. ${ }^{(24)}$ investigated patients with SIBO by culturing luminal secretions from the proximal small intestine and measuring concentrations of luminal interferon- $\gamma$, interleukin (IL)-6, and TNF- $\alpha$ and found that the mucosal production of IL-6 was increased. However, it is possible to speculate that the secretion of intraluminal cytokines in patients with SIBO is not of sufficient magnitude to trigger a systemic inflammatory response.

No significant association between any of the symptoms and SIBO was observed in this study. A systematic review by Grace et al. ${ }^{(2)}$ reported diarrhea as the predominant symptom in SIBO, followed by abdominal pain and bloating. Other researchers also evaluated the possible clinical usefulness and predictive value of clinical complaints for the diagnosis of SIBO in various clinical settings and reported nonspecificity and low accuracy of symptoms for the diagnosis of SIBO, as they are also present in many individuals with other gastrointestinal conditions ${ }^{(19,25,26)}$. Thus, the exclusive assessment of symptoms cannot be used to identify the occurrence of SIBO in CD. In turn, considering the retrospective nature of this study, we cannot rule out the hypothesis that the complaints presented by the evaluated patients were identified and recorded at levels lower than the actual levels, which could bias the results corresponding to the symptoms presented. Another limitation of the present study is that endoscopic remission was not ruled out; therefore, in some cases, the symptoms may be caused by intestinal activity that was not detected by the methods used (i.e., CDAI, HBI, CRP and ESR). 
Concentrations of $\mathrm{H}_{2}$ and $\mathrm{CH}_{4}$ in the exhaled air after the administration of glucose are widely used for the diagnosis of $\mathrm{SIBO}^{(27)}$. Notably, in this retrospective study, both the amount of $\mathrm{H}_{2}$ and $\mathrm{CH}_{4}$ were measured in expired air, which increases the sensitivity of the breath test to detect the presence of $\mathrm{SIBO}^{(2,7)}$. Furthermore, $8 \%$ to $27 \%$ of humans have no measurable amount of $\mathrm{H}_{2}$ gas produced by their intestinal microbiota, producing only $\mathrm{CH}_{4}^{(7,28)}$, and $14 \%$ to $35 \%$ of colonic bacteria are methane producers, which increases the value of measuring the latter gas and not only expired $\mathrm{H}_{2}{ }^{(29)}$. Indeed, in our observations, five (15.1\%) patients with $\mathrm{CD}$ were identified as having SIBO by increased expired $\mathrm{CH}_{4}$ only.

The present study has several methodological limitations that could require the results found be reproduced in other studies. Because it is a cross-sectional study that assessed the occurrence of SIBO only at the time of the breath test, it may lead to results that do not reflect its actual prevalence because the clinical outcome of SIBO in patients with CD is unknown, and this condition may have an alternating course of spontaneous resolution and recurrence ${ }^{(4,16)}$. Another aspect to be considered is the fact that the sensitivity of the $\mathrm{H}_{2}$ and $\mathrm{CH}_{4}$ breath test for the diagnosis of SIBO ranges from $20 \%$ to $93 \%$ and the specificity ranges from $30 \%$ to $86 \%$ compared with aspiration and culture of small intestine secretions, which is the gold standard test for the diagnosis of this condition ${ }^{(5,7)}$. Consequently, we cannot exclude the presence of false-negative or false-positive results. However, the duodenal aspiration process is invasive, not widely available, costly and requires a longer time to complete, making it unfeasible in daily clinical practice ${ }^{(4,7)}$. Quantification of expired $\mathrm{H}_{2}$ and $\mathrm{CH}_{4}$ through the breath test is a simpler and easier to perform procedure, less expensive and widely applicable for the diagnosis of $\mathrm{SIBO}^{(1,5)}$.

Another factor that should be highlighted is that the number of patients with CD who presented SIBO may not reflect the actual prevalence of this condition in the overall community of $\mathrm{CD}$ patients. The patients included in the present study were followedup in a tertiary level medical care system, where typically there are more severe diseases with a greater propensity of complications that may lead to the occurrence of $\mathrm{SIBO}^{(6,17,20)}$. This is a relevant factor because it may lead to the occurrence of bias, resulting in a higher prevalence of SIBO in the individuals studied by us than in the overall population of patients with $\mathrm{CD}$. Also, we did not evaluate fecal calprotectin levels, endoscopic and cross-sectional exams for ruling out intestinal inflammation in this $\mathrm{CD}$ population. Studies evaluating endoscopic healing are necessary to determine the true relationship between SIBO and mucosal inflammation. Thus, our results should be interpreted within an appropriate context, considering the factors discussed above.

Lastly, further longitudinal and prospective studies are needed to assess whether the possible presence of symptomatic/ asymptomatic SIBO in CD leads to metabolic and nutritional disorders in these patients and what would be the clinical impact of the treatment of SIBO in patients with CD. In meanwhile, a reasonable strategy for implementation in clinical practice would be to perform an individualized screening for SIBO followed by appropriate treatment in patients with remission $\mathrm{CD}$ that present on disease course with persistent gastrointestinal symptoms and/or unexplained metabolic and nutritional disorders. This approach can contribute to improving the quality of care of patients with $\mathrm{CD}$.

\section{CONCLUSION}

SIBO was a highly prevalent condition in CD patients. In addition, a stenosing phenotype was a predictor of SIBO in this clinical scenario. Physicians need to remember this diagnostic possibility in patients with $\mathrm{CD}$, notably in those with fibrostenosing disease. Individualized screening followed by appropriate treatment is a suggested strategy to improve the quality of care of patients with $\mathrm{CD}$.

\section{Authors' contribution}

Bertges ER: acquisition of data, analysis and interpretation of data, drafting the article. Chebli JMF: conception and design of the study, analysis and interpretation of data, drafting the article, final approval of the version to be submitted.

\section{Orcid}

Erika Ruback Bertges: 0000-0002-2298-4640.

Júlio Maria Fonseca Chebli: 0000.0003.1527.0663.

Bertges ER, Chebli JMF. Prevalência e fatores associados ao supercrescimento bacteriano do intestino delgado em pacientes com doença de Crohn: estudo retrospectivo em um centro de referência. Arq Gastroenterol. 2020;57(3):283-8.

RESUMO - Contexto - O supercrescimento bacteriano de intestino delgado (SBID) parece ser comum em pacientes com doença de Crohn (DC). A taxa de SBID tem sido estimada entre 25-88\% neste cenário. Entretanto, diferenças demográficas, socioeconômicas e dos fatores relacionados à doença podem existir entre as populações da América do Sul e da América do Norte ou europeias que podem limitar a generalização destes achados, uma vez que os dados são derivados principalmente de estudos norte-americanos ou europeus. Objetivo - Estudar a prevalência e os preditores de SBID em pacientes ambulatoriais com DC. Métodos - Neste estudo retrospectivo os registros médicos de 110 pacientes com DC que haviam sido submetidos ao teste respiratório do hidrogênio e metano expirados para o diagnóstico de SBID, entre junho de 2011 e junho de 2016, foram avaliados. Análise univariada foi realizada para investigar a potencial associação entre SBID com os dados demográficos, relacionados à DC e marcadores sistêmicos de inflamação (proteína C-reativa e velocidade de hemossedimentação). Resultados - A prevalência de SBID foi elevada em pacientes com DC (30\%). Os pacientes com e sem SBID foram comparáveis de acordo com os dados demográficos e de biomarcadores de inflamação sistêmica, bem como das características da DC, exceto pelo fenótipo estenosante, mais comum nos pacientes com DC e SBID (48,5\% vs 19,5\%, $P=0,001)$. Conclusão - Em pacientes brasileiros com DC, SBID é uma condição altamente prevalente. O fenótipo estenosante demonstrou associação com o SBID. O planejamento de um screening individualizado seguido por tratamento apropriado para SBID deve ser incluído como parte da melhoria na qualidade de cuidados a ser oferecida para os pacientes com DC.

DESCRITORES - Doenças inflamatórias intestinais. Doença de Crohn. Intestino delgado, microbiologia. Infecções bacterianas. Dados demográficos. 


\section{REFERENCES}

1. Bures J, Cyrany J, Kohoutova D, Förstl M, Rejchrt S, Kvetina J, et al. Small intestinal bacterial overgrowth syndrome. World J Gastroenterol. 2010;16:2978-90.

2. Grace E, Shaw C, Whelan K, Andreyev HJ. Review article: small intestinal bacterial overgrowth-prevalence, clinical features, current and developing diagnostic tests, and treatment. Aliment Pharmacol Ther. 2013;38:674-88.

3. Klaus J, Spaniol U, Adler G, Mason RA, Reinshagen M, von Tirpitz CC. Small intestinal bacterial overgrowth mimicking acute flare as a pitfall in patients with Crohn's Disease. BMC Gastroenterol. 2009;9:61.

4. Rezaie A, Pimentel M, Rao SS. How to Test and Treat Small Intestinal Bacterial Overgrowth: an Evidence-Based Approach. Curr Gastroenterol Rep. 2016;18:8.

5. Khoshini R, Dai SC, Lezcano S, Pimentel M. A systematic review of diagnostic tests for small intestinal bacterial overgrowth. Dig Dis Sci. 2008;53:1443-54.

6. Mishkin D, Boston FM, Blank D, Yalovsky M, Mishkin S. The glucose breath test: a diagnostic test for small bowel stricture(s) in Crohn's disease. Dig Dis Sci. 2002;47:489-94.

7. Gasbarrini A, Corazza GR, Gasbarrini G, Montalto M, Di Stefano M, Basilisco G, et al.; 1st Rome H2-Breath Testing Consensus Conference Working Group. Methodology and indications of H2-breath testing in gastrointestinal diseases: the Rome Consensus Conference. Aliment Pharmacol Ther. 2009;29 (Suppl 1):1-49.

8. Chebli JMF, de Abreu NC, Chebli LA, Reboredo MM, Pinheiro HS. Intestinal spirochetosis: an unusual cause of IBD flare-up during anti-TNF therapy. Int J Colorectal Dis. 2016;31:745-6.

9. Enko D, Halwachs-Baumann G, Stolba R, Mangge H, Kriegshäuser G. Refining small intestinal bacterial overgrowth diagnosis by means of carbohydrate specificity: a proof-of-concept study. Therap Adv Gastroenterol. 2016;9:265-72.

10. Castiglione F, Del Vecchio Blanco G, Rispo A, Petrelli G, Amalfi G, et al. Orocecal transit time and bacterial overgrowth in patients with Crohn's disease. J Clin Gastroenterol. 2000;31:63-6.

11. Lee JM, Lee KM. Endoscopic Diagnosis and Differentiation of Inflammatory Bowel Disease. Clin Endosc. 2016;49:370-5.

12. Silverberg MS, Satsangi J, Ahmad T, Arnott ID, Bernstein CN, Brant SR, et al. Toward an integrated clinical, molecular and serological classification of inflammatory bowel disease: report of a Working Party of the 2005 Montreal World Congress of Gastroenterology. Can J Gastroenterol. 2005;19 (Suppl A): 5A-36A.

13. Walsh AJ, Bryant RV, Travis SP. Current best practice for disease activity assessment in IBD. Nat Rev Gastroenterol Hepatol. 2016;13:567-79.

14. Freeman HJ. Natural history and long-term clinical course of Crohn's disease. World J Gastroenterol. 2014;20:31-6.

15. Rana SV, Sharma S, Malik A, Kaur J, Prasad KK, Sinha SK, et al. Small intestinal bacterial overgrowth and orocecal transit time in patients of inflammatory bowel disease. Dig Dis Sci. 2013;58:2594-8.
16. Castiglione F, Rispo A, Di Girolamo E, Cozzolino A, Manguso F, Grassia R, et al. Antibiotic treatment of small bowel bacterial overgrowth in patients with Crohn's disease. Aliment Pharmacol Ther. 2003;18:1107-12.

17. Shah A, Morrison M, Burger D, Martin N, Rich J, Jones M et al. Systematic review and meta-analysis: the prevalence of small intestinal bacterial overgrowth in inflammatory bowel disease. Aliment Pharmacol Ther. 2019;49:624-35.

18. Ricci JER, Chebli, LA, Ribeiro TCR, Castro ACS, Gaburri PD, Pace FHL, et al. Small-Intestinal Bacterial Overgrowth is Associated With Concurrent Intestinal Inflammation But Not With Systemic Inflammation in Crohn's Disease Patients. J Clin Gastroenterol. 2018;52:530-36.

19. Greco A, Caviglia GP, Brignolo P, Ribaldone DG, Reggiani S, Sguazzini C, et al. Glucose breath test and Crohn's disease: Diagnosis of small intestinal bacterial overgrowth and evaluation of therapeutic response. Scand J Gastroenterol. 2015;50:1376-81.

20. Sánchez-Montes C, Ortiz V, Bastida G, Rodríguez E, Yago M, Beltrán B, et al. Small intestinal bacterial overgrowth in inactive Crohn's disease: influence of thiopurine and biological treatment. World J Gastroenterol. 2014;20:1399-4003.

21. Neut C, Bulois P, Desreumaux P, Membré J-M, Ledermann E, Gam- biez L, et al. Changes in the Bacterial Flora of the Neoterminal Ileum After Ileocolonic Resektion for Crohn's Disease. Am J Gastroenterol. 2002,97:939-46.

22. Lee JM, Lee KM, Chung YY, Lee YW, Kim DB, Sung HJ, et al. Clinical significance of the glucose breath test in patients with inflammatory bowel disease. $\mathrm{J}$ Gastroen- terol Hepatol. 2015;30:990-4.

23. Shanab AA, Scully P, Crosbie O, Buckley M, O’Mahony L, Shanahan F, et al. Small intestinal bacterial overgrowth in nonalcoholic steatohepatitis: association with toll-like receptor 4 expression and plasma levels of interleukin 8. Dig Dis Sci. 2011;56:1524-34.

24. Riordan SM, McIver CJ, Wakefield D, Duncombe VM, Bolin TD, Thomas MC Mucosal cytokine production in small-intestinal bacterial overgrowth. Scand J Gastroenterol. 1996;31:977-84.

25. Jacobs C, Coss Adame E, Attaluri A, Valestin J, Rao SS. Dysmotility and proton pump inhibitor use are independent risk factors for small intestinal bacterial and/ or fungal overgrowth. Aliment Pharmacol Ther. 2013;37:1103-11.

26. Signoretti M, Stigliano S, Valente R, Piciucchi M, Delle Fave G, Capurso G. Small intestinal bacterial overgrowth in patients with chronic pancreatitis. J Clin Gastroenterol. 2014;48(Suppl 1):S52-S55.

27. Rezaie A, Buresi M, Lembo A, Lin H, McCallum R, Rao S, et al. Hydrogen and methane-based breath testing in gastrointestinal disorders: The North American Consensus. Am J Gastroenterol. 2017;112:775-8.

28. Triantafyllou K, Chang C, Pimentel M. Methanogens, methane and gastrointestinal motility. J Neurogastroenterol Motil. 2014;20:31-40.

29. Ghoshal UC, Park H, Gwee KA. Bugs and irritable bowel syndrome: the good, the bad and the ugly. J. Gastroenterol. Hepatol. 2010;25:244-51. 